\title{
Rietveld refinements, Impedance spectroscopy and phase transition of the polycrystalline $\mathrm{ZnMoO}_{4}$ ceramics
}

\author{
H. Ait ahsaine ${ }^{a^{*}}$, M. Zbair ${ }^{c}$, M. Ezahri ${ }^{a}$, A. Benlhachemi ${ }^{a}$, M. Arab ${ }^{b}$, B. Bakiz ${ }^{a}$, F. Guinneton ${ }^{b}$, J- \\ R.Gavarrib \\ ${ }^{a}$ Laboratoire Matériaux et Environnement LME, Faculté des Sciences, Université Ibn Zohr, BP 8106, Cité Dakhla, \\ Agadir, Maroc \\ ${ }^{\mathbf{b}}$ Institut Matériaux Microélectronique et Nanosciences de Provence, IM2NP, UMR CNRS 6242, Université de Toulon, \\ BP 20132, 83957, La Garde Cedex, France \\ ${ }^{\mathrm{c}}$ Laboratoire de catalyse et corrosion des matériaux, Université ChouaibDoukkali, Faculté des sciences El Jadida, BP. \\ 20, El Jadida 24000,Maroc \\ "Corresponding author. : H. Ait ahsaine a.hassan@uiz.ac.ma
}

\begin{abstract}
The triclinic phase of zinc molybdate $\alpha-\mathrm{ZnMoO}_{4}(\mathrm{ZMO})$ was synthesized by a simple coprecipitation method at $600^{\circ} \mathrm{C}$. The crystal structure of the obtained polycrystalline sample of ZMO was characterized by X-ray diffraction (XRD) and Rietveld calculations using the space group P-1. The electrical properties of $\alpha-\mathrm{ZnMoO}_{4}$ compacted pellets were determined at room temperature from Electrical Impedance Spectrometry (EIS), in the temperature range of $400^{\circ} \mathrm{C}$ to $700^{\circ} \mathrm{C}$. Nyquist representations were interpreted in terms of two types of electrical circuits, involving a high frequency bulk component and a low frequency Warburg component. Analyses of the frequency dependence of the real and imaginary impedance show a non-debye type relaxation. A phase transition corresponding to the allotropic transformation triclinic-monoclinic $(\alpha \rightarrow \beta)$ of $\mathrm{ZnMoO}_{4}$ was observed in the temperature range of 450 to $500^{\circ} \mathrm{C}$, with a variation of activation energies. The Warburg component is discussed in terms of electrode surface reactions.
\end{abstract}

\section{Keywords}

Zinc molybdate, Non-Debye relaxation, Electrical impedance spectroscopy, Phase transition 


\section{Introduction}

Tungstates and molybdates have multiple properties with interesting applications in various fields. It is well known that these types of materials overcome several phase transitions, thus they attracted considerable attention. For instance the $\mathrm{Bi}_{2} \mathrm{WO}_{6}$ compound has two phase transitions: one structural phase transition occurs at $660^{\circ} \mathrm{C}$ with a change in space group from $P 2{ }_{1} a b$ to $B 2 c b$, and another phase transition takes place at $960^{\circ} \mathrm{C}$ with the space group changing to $\mathrm{A} 2 / \mathrm{m}$ [1-3]. Likewise, a phase transition occurs for the Bismuth molybdate $\mathrm{Bi}_{2} \mathrm{MoO}_{6}$ compound (space group $P 2{ }_{1} a b$ ) at $640^{\circ} \mathrm{C}$ [4] or $680^{\circ} \mathrm{C}$ [1], also this irreversible phase transition takes place with a space group changing to $P 2_{1} / c$. Zinc Molybdate $\mathrm{ZnMoO}_{4}(\mathrm{ZMO})$ is one of the molybdate family and presents some similarities with these Aurivillius-Type compounds.

Electrical Impedance spectroscopy (EIS) was used by many researchers to explain materials behavior: Ben Mohamed et al [5] used the EIS to identify the slope change in conductivity, they concluded that the two phase transitions of their compound are accompanied by a change of the conduction mechanism observed in the difference of activation energies. Bourja et al have also determined some phase transitions in the cerium and bismuth mix oxides using the impedance spectroscopy [6].

In the last years, zinc molybdate $\mathrm{ZnMoO}_{4}$ was investigated for its luminescence properties [7-10], for applications in bolometers, scintillation detectors [11-15], humidity sensors [16], photocatalysis [17-19], microwave dielectric devices [20] and battery electrodes [21].However, this material presents different structures depending on the elaboration conditions. Traditionally two phases $\alpha-\mathrm{ZnMoO}_{4}$ and $\beta-\mathrm{ZnMoO}_{4}$, with triclinic and monoclinic structures respectively, have been synthesized by different techniques, such as hydrothermal method [22,18,23], solid state reaction [24-29], citrate complex precursors [30], co-precipitation method [31-33], electrospinning calcination method [34] and electrochemistry assisted ablation laser method [35].

In the case of the stabilized $\alpha$ phase, Goake et al. [36] observed a slight change in DSC analyses, they inferred a phase transition at $\mathrm{Tc}=735 \mathrm{~K}$ or $\Theta \mathrm{c}=462^{\circ} \mathrm{C}$. This phase transition corresponded to the transformation of a low temperature triclinic structure (the $\alpha$-phase), into a high temperature monoclinic structure (the $\beta$-phase). The triclinic $\alpha$-phase $[37,38]$ was characterized by structural groups $\left[\mathrm{ZnO}_{6} / \mathrm{MoO}_{4}\right]$ with tetrahedral $\mathrm{MoO}_{4}{ }^{2-}$ anions. The monoclinic $\beta$-phase [39] was described by distorted groups $\left[\mathrm{ZnO}_{6}\right] /\left[\mathrm{MoO}_{6}\right]$ with octahedral $\mathrm{MoO}_{6}{ }^{6-}$ anions. It should be recalled 
that the phase transition is characterized by the strong transformation of molecular groups $\mathrm{MoO}_{4}$ (low temperature phase) into molecular groups $\mathrm{MoO}_{6}$. The $\beta$-phase was also synthesized directly via hydrothermal route as a metastable phase (obtained at room temperature) [18]. The monoclinic $\beta$ phase was characterized by an indirect band gap around $2.48-2.68 \mathrm{eV}$, and was evaluated as a photocatalytic material [24]. The triclinic $\alpha-\mathrm{ZnMoO}_{4}$ band gap was determined by Keereeta $e t$ al. [34] with a value of $3.3 \mathrm{eV}$.

This present study reports for the first time the electrical behavior at high temperature of ZMO. The main aim of our study is to investigate the effects of the phase transition on the sintered ZMO pellets conductivity. As a first step, we synthesized the polycrystalline sample, we optimized its crystallization, then, we refined the structure using the Rietveld refinements. Finally, in a second step, electrical impedance spectroscopy was used to characterize the evolution of conductivity as a function of temperature.

\section{Experimental section.}

Synthesis of the material: Zinc molybdate was synthesized via a co-precipitation method using sodium molybdate $\left(\mathrm{Na}_{2} \mathrm{MoO}_{4} \cdot 2 \mathrm{H}_{2} \mathrm{O}\right)$ and zinc nitrate $\left(\mathrm{Zn}\left(\mathrm{NO}_{3}\right)_{3} \cdot 6 \mathrm{H}_{2} \mathrm{O}\right)$. A mixed aqueous solution was prepared by dissolving required weights of appropriate amounts of $\mathrm{Zn}\left(\mathrm{NO}_{3}\right)_{3} \cdot 6 \mathrm{H}_{2} \mathrm{O}$ and Sodium molybdate $\mathrm{Na}_{2} \mathrm{MoO}_{4} \cdot 2 \mathrm{H}_{2} \mathrm{O}$ in $50 \mathrm{ml}$ of distilled water, in separated beakers with magnetic stirring. Then sodium molybdate solution was gradually added to the zinc nitrate solution. The resulting white precipitate was filtered and washed several times with distilled water and ethanol, and finally, the obtained powder were calcined during 3 hours at $600^{\circ} \mathrm{C}$ with a cooling rate of $20^{\circ} \mathrm{C} / \mathrm{min}$.

X-Ray diffraction: The X-Ray diffraction (XRD) patterns were collected using an Empyrean Panalytical diffractometer operating at $45 \mathrm{kV} / 35 \mathrm{~mA}$, using $\mathrm{Cu}-\mathrm{K} \alpha$ radiation with $\mathrm{Ni}$ filter, and working in continuous mode with a step size of $0,013^{\circ} 2 \theta$. Data suitable for Rietveld refinements were collected over a range $5-80^{\circ} 2 \theta$.

Electrical Impedance Spectroscopy (EIS): The electrical impedance spectroscopy is currently used to describe electrical properties in polycrystalline samples. This technique was recently applied to a phase transition $[5,6]$. Our study was performed using an electrical impedance spectrometer (Solartron Impendance meter SI 1260) coupled to an electrical cell operating under air. All 
measurements were carried out in the temperature range of 100 to $750^{\circ} \mathrm{C}$. The $\mathrm{ZMO}-600$ sample was a cylindrical pellet (diameter $13.02 \pm 0.1 \square \mathrm{mm}$, thickness $2.17 \pm 0.05 \square \mathrm{mm}$ ) initially compacted under ambient conditions. The experimental density of $3.87 \mathrm{~g} . \mathrm{cm}^{-3}$ represents $90 \%$ of the theoretical density $4.3 \mathrm{~g} . \mathrm{cm}^{-3}$. The pellet was placed between two cylindrical platinum electrodes and was pressed in a specific cell. The cell was placed in an isotherm furnace operating up to $750^{\circ} \mathrm{C}$.

The electrical analyses were carried out in the frequency range $(\omega=2 \pi v) 1$ to $10^{7} \square \mathrm{Hz}$, with an alternating current associated with a maximum voltage of $1 \square \mathrm{V}$. The sample was stabilized for 20 minutes at a fixed temperature and the recording time for the frequency range was of 20 minutes. To ensure thermal stabilization, the sample was subjected to three successive measuring cycles (one temperature rise and drop for each cycle). The final impedance data were chosen during heating mode of the third cycle, as being representative of a stabilized sample.

\section{Results And Discussion}

\section{III.1. X-Ray Diffraction analyses}

Figure 1 presents the XRD pattern of the sample thermally treated at $600^{\circ} \mathrm{C}$, the identification of this phase was firstly obtained from the comparison with the standard JCPDS files (Joint Committee standards for Powder Diffraction) in which the standard phase ZMO was referenced, This first identification allowed attributing (h,k,l) Miller indices to Bragg peaks. All the diffraction peaks correspond to the $\mathrm{ZnMoO}_{4}$ P-1 structure according the JCPDS file 70-5387. In order to determine the crystal structure of the as-synthesized ZMO-600 ceramic, Rietveld refinements were performed using General Structure Analysis System (GSAS) Software [40] accessed through the EXPGUI [41] graphical user interface which allows refinement of atomic coordinates, site occupancies and atomic displacement parameters, as well as profile parameters (instrument parameters, background parameters, lattice constants and peak shape). The minimization was carried out using the reliability index parameters such as Braggs factors $\left(\boldsymbol{R}_{\text {Bragg }}\right)$ comparing the calculated and observed intensities (Ical and Iobs), $\boldsymbol{R}_{\exp }$ expected factors, $\boldsymbol{R}_{\boldsymbol{w}}$ and the goodness of fit $\boldsymbol{G o F}$. All these parameters were used as numerical criteria of the quality of the fit of calculated to experimental diffraction data, and are represented by relations: 


$$
\begin{aligned}
& \mathbf{R}_{\mathbf{B}}=\mathbf{1 0 0} .\left\{\sum\left(\mathbf{I}^{\mathrm{obs}}-\mathbf{I}^{\mathrm{calc}}\right) / \sum\left(\mathbf{I}^{\mathrm{obs}}\right)\right\} \\
& \mathbf{R}_{\text {exp }}=100 .\left\{\left[(\mathbf{N}-\mathbf{P}+\mathrm{C}) / \sum \mathbf{w}_{\mathrm{i}}\left(\mathbf{y}_{\text {iobs }}\right)^{2}\right]^{1 / 2}\right\}
\end{aligned}
$$

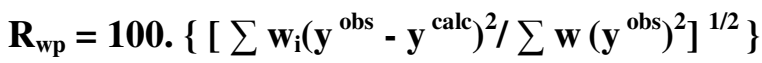

Where $N, P$ and $C$ are the number of observations, parameters and constraints respectively.

\section{Figure 1: XRD pattern of $\alpha-\mathrm{ZnMoO}_{4}$ obtained in room conditions, after thermal treatments at $600^{\circ} \mathrm{C}$, during 3 hours.}

figure 1 (Inset structure) presents the crystal structure of the $\mathrm{ZMO}$ compound, There is six $\mathrm{ZnMoO}_{4}$ per unit cell. Each of the three crystallographically independent Mo atoms is surrounded by distorted tetrahedral of oxygen atoms and two of the independent zinc atoms occupy distorted octahedral of oxygen atoms.

The results of the Rietveld refinements are presented in Table 1 where the refined lattice parameters are reported. The initial atom coordinates have been exported from the structural results of authors [38] on single crystal. These coordinates have been refined: oxygen and zinc/molybdenum coordinates were refined, which led to a significant goodness of fit. Moreover, the fit parameters $\left(R_{\mathrm{wp}}, \mathrm{R}_{\mathrm{p}}, \mathrm{R}_{\mathrm{exp}}\right.$, and $\left.\chi^{2}\right)$ are quite reliable. The main interatomic distances are given in Table 2 , the Mo-O distances vary between 1.7076(1) and 1.8050(1) $\AA$ and the octahedral Zn-O distances range from 1.9957(1) to 2.1567(1) A. Figure 2 illustrates the calculated and observed diffraction profiles of $\mathrm{ZnMoO}_{4}$ compound.

All these results are in full agreement with the crystal structure proposed by Reichelt et al. [38], determined from X-ray diffraction on a single crystal.

Table 1: Refined structural parameters for triclinic $\alpha-\mathrm{ZnMoO}_{4}$ phase (space group P-1) 
Table 2: Main interatomic distances $(\AA)$ for the $\alpha-\mathrm{ZnMoO}_{4}$ ceramics

Figure 2: Calculated and observed diffraction profiles, from XRD Rietveld refinements of $\alpha-\mathrm{ZnMoO}_{4}$ thermally treated at $600^{\circ} \mathrm{C}$.

\section{III.2. Electrical Impedance Spectroscopy}

\section{Impedance analyses}

Figure 3 represents a series of Nyquist representations obtained from $300^{\circ} \mathrm{C}$ to $700^{\circ} \mathrm{C}$. From $300^{\circ} \mathrm{C}$ to $400^{\circ} \mathrm{C}$, the plots can be fitted by unique Nyquist semicircles, associated with grain-core conduction. Above $400^{\circ} \mathrm{C}$, we observe a new contribution at low frequency corresponding to conduction and diffusion at the electrodes.

Figure 3: Nyquist representation for the $\alpha-\mathrm{ZnMoO}_{4}$ sample, as a function of temperature $300^{\circ} \mathrm{C} \leq \Theta \leq 700^{\circ} \mathrm{C}$.

The Nyquist plots were interpreted and fitted using Zview software [43] by a classical equivalent circuit with impedance including constant phase elements [42] and resistance in parallel. RC parallel circuits and constant phase elements $\mathrm{Z}(\mathrm{CPE})$ were tested on Nyquist experimental data. At low temperature $\Theta<400^{\circ} \mathrm{C}$, the impedance of such parallel $\mathrm{R} / \mathrm{CPE}$ is well fitted. However, in the high 
temperature range $\Theta>400^{\circ} \mathrm{C}$, the linear contribution at low frequencies corresponds to a specific Warburg model described through a specific impedance $Z_{W}$ depending on the diffusion mechanism at the electrode -material interfaces (Figure 4).

The electrical analyzes were performed by separating the impedances associated with the core of the material (including grain boundaries) and those related to the electrodes ( $\mathrm{Z}$ and $\mathrm{Z}_{\mathrm{W}}$ for bulk and Warburg impedances respectively).

\section{Figure 4: Fit of Nyquist data obtained at $600^{\circ} \mathrm{C}$, for the $\alpha-\mathrm{ZnMoO}_{4}$ sample, equivalent circuit (inset) with Warburg component.}

The corresponding conductivities were determined from the formula: $\sigma=(\mathrm{e} / \mathrm{S}) / \mathrm{R}$ where $\mathrm{S}$ is the section and $\mathrm{e}$ is the thickness of the pellet. The electrical impedance $\mathrm{Z}$ is given by $1 / \mathrm{Z}=1 / \mathrm{R}+$ $\mathrm{A}(\mathrm{j} . \omega)^{\mathrm{n}}$, where $n$ is an exponent depending on heterogeneity of material $(0 \leq \mathrm{n} \leq 1)$, and $\mathrm{A}$ is a constant characteristic of polarization (if $\mathrm{n}=1, \mathrm{~A}$ is the classical capacitance).

Table 3 reports the parameters relative to the bulk impedance analysis: the parameters $\mathrm{R}, \mathrm{A}$ and $\mathrm{n}$ are respectively the resistance, the polarization parameter and the exponent characteristic of the CPE term $(j \omega)^{\mathrm{n}}$.

Table 3: Electrical characteristics of ZMO-600 pellet. Bulk impedance analysis: CPE terms $\mathrm{A}$ (in $\Omega^{-1} \cdot \mathrm{Hz}^{-\mathrm{n}}$ unit) and $\mathrm{CPE}$ exponents $\mathrm{n}$, as a function of temperatures $300^{\circ} \mathrm{C} \leq \Theta \leq \mathbf{7 0 0}^{\circ} \mathrm{C}$. Model: $1 / Z=1 / R+A \cdot(j \omega)^{n}$

The Warburg element [44-48] can be expressed in a generalized form as follows: 


$$
\mathrm{Z}_{\mathrm{W}}=\mathrm{R}_{\mathrm{W}} \cdot \operatorname{Tanh}\left[\left(\mathrm{j} \mathrm{A}_{\mathrm{W}} \omega\right)^{\mathrm{m}}\right] /\left(\left[\left(\mathrm{j} \mathrm{A}_{\mathrm{W}} \omega\right)^{\mathrm{m}}\right)\right.
$$

In this expression, $\mathrm{R}_{\mathrm{W}}$ is the Warburg resistance depending on diffusion characteristics at the electrode/material interface, $m$ is the characteristic exponent, $A_{W}=L^{2} / D$ is related to the chemical diffusion coefficient $\mathrm{D}\left(\mathrm{m}^{2} \mathrm{~s}^{-1}\right)$, and to the characteristic length $\mathrm{L}$ of reaction process (effective diffusion thickness). Table 4 reports the values of $R_{W}, A_{W}$ and exponent $m$ obtained from this model.

Table 4: Warburg parameters $R_{W}, A_{W}$ and $m$, as a function of temperatures $300^{\circ} \mathrm{C} \leq \Theta \leq$ 700 ${ }^{\circ}$. Model: $Z_{W}=R_{W} \cdot \operatorname{Tanh}\left[\left(j A_{W} \omega\right)^{m}\right] /\left(\left[\left(j A_{W} \omega\right)^{m}\right)\right.$

\section{Impedance vs. Frequency analysis}

Figure 5 reports the variation of real and imaginary impedances as a function of frequency and temperature. The real Z' decreases with increasing temperature till a certain fixed frequency suggesting a notable reduction in the bulk resistance. The real impedance Z' attains a plateau at higher frequencies which implies a possible release of space charges meaning the absence of frequency relaxation in the ceramic $[49,50]$. A peaking behavior can be observed for all the selected spectra, the peak maximum shifts towards higher frequencies as a function of temperature. The imaginary Z" attains a maximum at certain frequency, then it decreases with increasing temperature to a fixed value at higher frequencies with peak broadening. The full width at half maximum (FWHM) calculated from the frequency dependence is greater than 1.141 decade (for ideal Debye type relaxation), this deviation clearly indicates the presence of non-Debye type relaxation in the sample [51]. These results explain the presence of relaxation process and the temperature dependence of the relaxation phenomenon in the pellet sample [52]. The relaxation process occurs due to the presence of immobile charges at low temperatures and of additional defects and vacancies at higher temperatures $[53,54]$.

Figure 5: Variation of real and imaginary impedance (i.e $Z$ ' and $Z$ '') with frequency at selected temperatures. 


\section{Conductivity analysis}

In Figure 6 representing the logarithm of conductivity $\sigma$ versus 1/T, or logarithm of $\sigma . T$ versus 1/T, we clearly observe a modification in the temperature range 440 to $500^{\circ} \mathrm{C}$. In the linear part of the curves (at low or high temperatures), the activation energies are different. In the transition range from 440 to $500{ }^{\circ} \mathrm{C}$, the progressive variation of conductivity can be interpreted in terms of specific "progressive jumps" characteristic of a first order transition, with coexistence of two phases (the so called $\alpha$ and $\beta$ phases). We have evaluated the conductivity variation due to the transition, by extrapolating the two linear parts of $\log (\sigma)$ curves at high and low temperatures: close to the transition point, the two lines are separated by a $\Delta \sigma / \sigma$ relative variation of about $0.45 \pm 0.05$.

This double modification can be interpreted in terms of coupling of the phase transition at $\Theta \mathrm{c}=$ $450^{\circ} \mathrm{C}$ with the modification of charge carriers associated with two different activation energies: the first one being due to extrinsic initial defects of the material, and the second one being due to major contribution of additional Schottky defects delivering additional mobile oxygen ions.

Figure 6: Evolution of sample conductivity in two Arrhenius representations, (a) $\log (\sigma)$ and (b) $\log (\sigma . \mathrm{T})$ versus $1 / \mathrm{T}\left(\mathrm{K}^{-1}\right)$. Activation energies determined in the linear parts of the curves.

Figure 7 shows the quasi-linear aspects of the curves $\log \left(\Sigma_{\mathrm{W}}\right)$ and $\log \left(\Sigma_{\mathrm{W}} \cdot \mathrm{T}\right)$ versus $1 / \mathrm{T}$, where $\Sigma_{\mathrm{W}}$ is the conductance $\left(1 / \mathrm{R}_{\mathrm{W}}\right)$. This can be associated with a classical Arrhenius behavior, with $\Sigma_{\mathrm{W}}$ or $\Sigma_{\mathrm{W}} \cdot \mathrm{T}$ proportional to $\exp \left(-\mathrm{E}_{\mathrm{W}} / \mathrm{RT}\right)$ or $\exp \left(-\mathrm{E}_{\mathrm{W}} / \mathrm{RT}\right)$, where $\mathrm{E}_{\mathrm{W}}$ or $\mathrm{E}_{\mathrm{W}}$ ' could be the activation barriers for diffusion, at the electrode/material interface. Except in the temperature range $400{ }^{\circ} \mathrm{C}$ to $500^{\circ} \mathrm{C}$, a linear correlation is clearly observable. The activation energy can be ascribed to the transformation $\mathrm{O}^{\mathrm{x}}=1 / 2 \mathrm{O}_{2}+\mathrm{V}^{\circ \circ}+2 . \mathrm{e}^{\prime}$, occurring at the interfaces material/electrode. 
Figure 7: Evolution of Warburg conductance in two Arrhenius representations: $\log (\Sigma)$ and $\log (\Sigma . \mathrm{T})$ versus $1 / \mathrm{T}\left(\mathrm{K}^{-1}\right)$

For a better understanding of these observations, we report the activation energies for bulk and Warburg (electrodes) components in Table 5. In the case of the bulk component, the transition is observed through the change in activation energies in the two possible representations $\log (\Sigma)$ or $\log (\Sigma \mathrm{T})$. In the case of the Warburg component, no significant change is observed.

Table 5: Activation energies associated with bulk and Warburg components.

To interpret the electrical transition observed in our ZMO-600 sample: two types of models might be proposed. Generally, in the absence of any phase transition, if we assume that at least two types of charge carriers can coexist, the thermally activated conductivity can be expressed as follows:

$$
\begin{gathered}
\Rightarrow \sigma=\left(K_{1} / T\right) \cdot \exp \left(-E_{1} / R T\right)+\left(K_{2} / T\right) \cdot \exp \left(-E_{2} / R T\right) \\
\Rightarrow
\end{gathered}
$$

In the case of a material undergoing a phase transition at a temperature $T_{c}$, each parameter $K_{i}, E_{i}$ $(i=1,2)$ could be subjected to a modification as a function of $\mathrm{T}$.

However, another more classical model could be proposed in competition with the previous one, where $\mathrm{K}_{-}, \mathrm{K}_{+}$are in relation with $\mathrm{K}_{1}$ and $\mathrm{K}_{2}$, and where $\mathrm{E}_{-}, \mathrm{E}_{+}$are in relation with $\mathrm{E}_{1}$ and $\mathrm{E}_{2}$ :

$$
\begin{array}{ll}
\Rightarrow & \sigma_{-}(\mathrm{T}<\mathrm{Tc})=\left(\mathrm{K}_{-} / \mathrm{T}\right) \cdot \exp (-\mathrm{E} / \mathrm{RT}) \\
\Rightarrow & \sigma_{+}(\mathrm{T}>\mathrm{Tc})=\left(K_{+} / \mathrm{T}\right) \cdot \exp \left(-\mathrm{E}_{+} / \mathrm{RT}\right)
\end{array}
$$


This model was used to calculate the activation energies in Table 5. However, this simplified model cannot account for changes in the vicinity of the transition point.

It is the reason why we propose now to consider that the phase transition can have a direct consequence on the various types of charge carriers, due to initial extrinsic defects and on additional defects linked to Schottky-like defects, formed during heating the material and in equilibrium with oxygen of air.

To describe the first order transition at $\mathrm{T}_{\mathrm{c}}=733 \mathrm{~K}$, we postulate a modification of the $\left(\mathrm{K}_{1}, \mathrm{E}_{1}\right)$ and $\left(\mathrm{K}_{2}, \mathrm{E}_{2}\right)$ terms, occurring in a small temperature range between $\mathrm{T}_{\mathrm{c}}$ and $\mathrm{T}_{\mathrm{up}}$. In the case of a first order transition, a two-phase domain of temperature can be generally observed. Consequently, the $\mathrm{K}_{1}$ and $\mathrm{K}_{2}$ terms are subjected to increasing values of $\Delta \mathrm{K}_{1}$ and $\Delta \mathrm{K}_{2}$, while the enthalpy terms are subjected to decreasing values of $-\Delta \mathrm{E}_{1}$ and $-\Delta \mathrm{E}_{2}$ : these last decreasing values correspond to the structural modification allowing larger space for electron (and vacancy) mobilities, and weaker barriers for electron (and vacancy) jumps. In fact, to correctly describe the transition domain between $T_{c}$ and $\mathrm{T}_{\mathrm{up}}$, it was necessary to use empirical continuous evolution of these parameters. All parameters describing the phase transition have been reported in Table 6.

\section{Table 6: parameters of modeled conductivity}

Figure 8 shows the calculated curve $\log (\sigma)$ function of $1 / T$, fully similar to the experimental curve in the case of the $3^{\text {rd }}$ thermal cycle.

The functions allowing describing the transition domain:

$$
\begin{gathered}
K_{1,2}(T c<T<T u p)=K_{1,2}+\left(K_{1,2}-K_{1,2}\right) .\left(T-T_{c}\right) /\left(T_{u p}-T_{c}\right) \\
E_{1,2}(T c<T<T u p)=E_{1,2}-\left(E_{1,2}-E_{1,2}\right) .\left(T-T_{c}\right) /\left(T_{u p}-T_{c}\right)
\end{gathered}
$$

Figure 8: The calculated curve $\log (\sigma)$ using the proposed model 


\section{as a function of $1 / \mathrm{T}\left(\mathrm{K}^{-1}\right)$}

The $E_{1}$ and $E_{2}$ values are closely related to the experimental values $E$ - and E+ obtained by fitting independently each linear section of Figure 8. The $-\Delta \mathrm{E}_{1}$ and $-\Delta \mathrm{E}_{2}$ jumps are a second characteristic of the phase transition. The $\Delta \mathrm{K}_{1}$ and $\Delta \mathrm{K}_{2}$ variations are associated with the mobilities of charge carriers close to the transition temperature.

\section{Conclusion}

In this work, we have observed the phase transition in the $\mathrm{ZnMoO}_{4}$ ceramics through the study of electrical properties. The bulk conductivity is characterized by a complex modification occurring above the transition point (presently $\mathrm{Tc}=723 \mathrm{~K}$ or $\Theta_{\mathrm{c}}=450^{\circ} \mathrm{C}$ ). Using a model based on two behaviors of charge carriers, coupled with the phase transition mechanism, we have simulated the conductivity as temperature increases. The hypotheses based on the existence of modification of charge carriers mobilities at the transition point allow simulating a transition domain in which the conductivity progressively varies between the observed transition temperature $\Theta_{c}=450^{\circ} \mathrm{C}$, and the temperature $\Theta_{\text {up }}$ close to $500^{\circ} \mathrm{C}$, corresponding to the end of transition. Two enthalpies associated with two types of charge carriers have been introduced in the calculation: the transition affects these enthalpies. An additional result was obtained from the evolution of Warburg components: this clearly shows the presence of ionic conduction in the material directly related to oxygen vacancies and electrode reactions. The Warburg signal is characteristic of surface reactions at the electrode. An activation barrier has been determined for the diffusion mechanism.

\section{Acknowledgments}

A part of this work was financially supported by materials and environment laboratory (AgadirMorocco) by the Regional Council of Provence-Alpes-Côte d'Azur, by the General Council of Var 
and by Toulon Provence Mediterranean, and was conducted as part of a CNRS-CNRST project. The authors gratefully acknowledge the assistance of Mr. Y. Ben Smida.

\section{References}

[1] V.I. Voronkova, E.P. Kharitonova, O.G. Rudnitskaya, Refinement of $\mathrm{Bi}_{2} \mathrm{WO}_{6}$ and $\mathrm{Bi}_{2} \mathrm{MoO}_{6}$ polymorphism, J. Alloys Compd., 487 (2009), p. 274

[2] M. Maczka, L. Macalik, K. Hermanowicz, L. Kepiński, P. Tomaszewski, Phonon properties of nanosized bismuth layered ferroelectric material- $\mathrm{Bi}_{2} \mathrm{WO}_{6}$, J. Raman Spectrosc., 41 (2010), p. 1059 [3] N.A. McDowell, K.S. Knight, P. Lightfoot, Unusual High-Temperature Structural Behaviour in Ferroelectric $\mathrm{Bi}_{2} \mathrm{WO}_{6}$, Chem. Eur. J., 12 (2006), p. 1493

[4] N. Baux, R.N. Vannier, G. Mairesse, G. Nowogrocki, Oxide ion conductivity in $\mathrm{Bi}_{2} \mathrm{~W}_{1-\mathrm{x}} \mathrm{ME}_{\mathrm{x}} \mathrm{O}_{6-\mathrm{x} / 2}(\mathrm{ME}=\mathrm{Nb}, \mathrm{Ta})$, J. Solid State Ionics, 91 (1996), p. 243

[5] C. Ben Mohamed, K. Karoui, S. Saidi, K. Guidara, A. Ben Rhaiem, Electrical properties, phase transitions and conduction mechanisms of the $\left[\left(\mathrm{C}_{2} \mathrm{H}_{5}\right) \mathrm{NH}_{3}\right]_{2} \mathrm{CdCl}_{4}$ compound, Phys. B: Condens. Matter 451 (2014), P. 87

[6] L. Bourja, B. Bakiz, A. Benlhachemi, M. Ezahri, S. Villain, C. Favotto, J-R. Gavarri, Electrical Properties of a $\mathrm{CeO}_{2}-\mathrm{Mix}$ System Elaborated at $600^{\circ} \mathrm{C}$, Adv. Mater. Sci. Eng, Volume 2012 (2012), Article ID 452383, 11 pages

[7] L.S. Cavalcante, J.C. Sczancoski, M. Siu Li, E. Longo, J.A. Varela, $\beta-\mathrm{ZnMoO}_{4}$ microcrystals synthesized by the surfactant-assisted hydrothermal method: Growth process and photoluminescence properties, Colloid Surf A: Physicochem Eng Aspects, 396 (2012) 346-351 [8] D. Spassky, A. Vasil'ev, I. Kamenskikh, V. Kolobanov, V. Mikhailin, A. Savon, L. I. Ivleva, I. Voronina, L. Berezovskaya, Luminescence investigation of zinc molybdate single crystals, Phys Stat Sol A, 206 (2009) 1579-1583

[9] T.N. Nikolaenko, Y.A. Hizhnyi, S.G. Nedilko, Exited states of the luminescence centers in tungstate crystals, J. Lumin. 128 (2008) 807.

[10] L.I. Ivleva, I.S. Voronina, L.Y. Berezovskaya, P.A. Lykov, V.V. Osiko, L.D. Iskhakova, Growth and properties of $\mathrm{ZnMoO}_{4}$ single crystals, Crystallogr. Rep. 53 (2008) 1087

[11] V.B. Mikhailik, H. Kraus, D. Wahl, H. Ehrenberg, M.S. Mykhaylyk, Optical and luminescence studies of $\mathrm{ZnMoO}_{4}$ using vacuum ultraviolet synchrotron radiation, Nucl. Instrum. Methods Phys. Res., Sect. A, 562 (2006), p. 513 
[12] C. Arnaboldi, C. Brofferio, O. Cremonesi, L. Gironi, M. Pavan, G. Pessina, S. Pirro, E.

Previtali, A novel technique of particle identification with bolometric detectors, Astropart. Phys., 34 (2011), p. 797

[13] L. Gironi, C. Arnaboldi, J.W. Beeman, O. Cremonesi, F.A. Danevich, V.Y. Degoda, L.I.

Ivleva, L.L. Nagornaya, M. Pavan, G. Pessina, S. Pirro, V.I. Tretyak, J. Tupitsyna, Performance of $\mathrm{ZnMoO}_{4}$ crystal as cryogenic scintillating bolometer to search for double beta decay of molybdenum, J. Instrum., 5 (2010), p. 11007

[14] L.L. Nagornaya, F.A. Danevich, A.M. Dubovik, B.V. Grinyov, S. Henry, V. Kapustyanyk, H. Kraus, D.V. Poda, V.M. Kudovbenko, V.B. Mikhailik, M. Panasyuk, O.G. Polischuk, V. Rudyk, V. Tsybulskyi, I.A. Tupitsyna, Y.Y. Vostretsov, Tungstate and Molybdate Scintillators to Search for Dark Matter and Double Beta Decay, IEEE. Trans. Nucl. Sci., 56 (2009), p. 2513

[15] J.W. Beeman, F. Bellini, S. Capelli, L. Cardani, N. Casali, I. Dafinei, S. Di Domizio, F. Ferroni, E.N. Galashov, L. Gironi, F. Orio, L. Pattavina, G. Pessina, G. Piperno, S. Pirro, V.N. Shlegel, Ya.V. Vasilyev, C. Tomei, M. Vignati, $\mathrm{ZnMoO}_{4}$ : A promising bolometer for neutrinoless double beta decay searches, Astropart. Phys 35 (2012) 813-820

[16] A.M.E.S. Raj, C. Mallika, K. Swaminathan, O.M. Sreedharan, K.S. Nagaraja, Zinc(II) oxidezinc(II) molybdate composite humidity sensor, Sens. Actuators B. Chem., 81 (2002) 229-236 [17] C.C. Chen, Y.R. Jiang, K.H. Chang, The Hydrothermal Synthesis of $\beta-Z n M o M_{4}$ for UV or Visible-Light-Responsive Photocatalytic Dedradation of Victoria Blue R, Adv. Mater. Res., 557 (2012), p. 761

[18] L. Lv, W. Tong, Y. Zhang, Y. Su, X. Wang, Metastable monoclinic ZnMoO 4 : hydrothermal synthesis, optical properties and photocatalytic performance, J. Nanosci. Nanotechnol., 11 (2011), p. 9506

[19] Y. Li, G. Weisheng, B. Bo, G. Kaijie, IEEE Int. Conf. Energy Environ. Technol., 3 (2009) 67267

[20] J. Guo, D. Zhou, H. Wang, X. Yao, Microwave dielectric properties of $(1-x) \mathrm{ZnMoO}_{4}-x \mathrm{TiO}_{2}$ composite ceramics, J. Alloys Compd., 509 (2011), p. 5863

[21] N.N. Leyzerovich, K.G. Bramnik, T. Buhrmester, H. Ehrenberg, H. Fuess, Electrochemical intercalation of lithium in ternary metal molybdates $\mathrm{MMoO}_{4}(\mathrm{M}: \mathrm{Cu}, \mathrm{Zn}, \mathrm{Ni}$ and Fe), J. Power Sources, 127 (2004) 76-84

[22] L.S. Cavalcante, E. Moraes, M.A.P. Almeida, C.J. Dalmaschio, N.C. Batista, J.A. Varela, E. Longo, M. Siu Li, J. Andrés, A. Beltrán, A combined theoretical and experimental study of 


\section{Accepted Manuscript}

electronic structure and optical properties of $\beta-\mathrm{ZnMoO}_{4}$ microcrystals, J. Polyhedron 54 (2013) 1325

[23] Yu-Rou Jiang, Wenlian William Lee, Kung-Tung Chen, Ming-Chien Wang, Ken-Hao

Chang, Chiing-Chang Chen, Hydrothermal synthesis of $\beta-\mathrm{ZnMoO}_{4}$ crystals and their photocatalytic degradation of Victoria Blue R and phenol, J Taiwan Inst Chem Eng 45 ( 2014) 207-218

[24] N. Sotani, T. Suzuki, K. Nakamura, K. Eda, S. Hasegawa, Change in bulk and surface structure of mixed $\mathrm{MoO}_{3}-\mathrm{ZnO}$ oxide by heat treatment in air and in hydrogen, J. Mater. Sci., 36 (2001), p. 703

[25] A.L. Kruglyashov, E.M. Skou, Ionic conductivity of compounds in the system $\mathrm{Na}_{2} \mathrm{MoO}_{4}$ $\mathrm{ZnMoO}_{4}$, Solid State Ionics, 28 (1988), p. 233

[26] A. Manthiram, J. Gopalakrishnan, New $\mathrm{A}^{2+} \mathrm{Mo}^{4+} \mathrm{O}_{3}$ oxides with defect spinel structure, Mater. Res. Bull., 15 (1980), p. 207

[27] AM. Dubovik, Y.Y. Vostretsov, B.V. Grinyov, F.A. Danevich, H. Kraus, L.L. Nagornaya, V.B. Mikhailik, I.A. Tupitsyna, Research and Development of ZnBO_\{4\} (B =W, Mo) Crystal Scintillators for Dark Matter and Double Beta Decay Searching, Acta Phys. Pol. A, 117 (2010), p. 15

[28] C.V. Bhuvana, B. Viswanathan, M.V.C. Sastri, Studies on the catalytic oxidation of propylene on ferric molybdate, Reaction Kinetics and Catalysis Letters, Indian J. Chem., 1A (1979), p. 385 [29] M. Kurzawa, M. Bosacka, Reactivity of $\mathrm{Zn}_{3} \mathrm{~V}_{2} \mathrm{O}_{8}$ Towards $\mathrm{ZnMoO}_{4}$ in the Solid State, J. Therm. Anal. Calorim., 60 (2000) 177-181

[30] J.H. Ryu, S.M. Koo, J.W. Yoon, C.S. Lim, K.B. Shim, Synthesis of nanocrystalline $\mathrm{MMoO}_{4}(\mathrm{M}=\mathrm{Ni}, \mathrm{Zn})$ phosphors via a citrate complex route assisted by microwave irradiation and their photoluminescence, Mater. Lett., 60 (2006), p. 1702

[31] A. Sen, P. Pramanik, Low-temperature synthesis of nano-sized metal molybdate powders, Mater. Lett., 50 (2001) 287-294

[32] C. Peng, L. Gao, S. Yang, J. Sun, A general precipitation strategy for large-scale synthesis of molybdate nanostructures, Chem. Commun., 43 (2008) 5601-5603

[33] Zahra Shahri, Mehdi Bazarganipour, MasoudSalavati-Niasari, Controllable synthesis of novel zinc molybdate rod-like nanostructures via simple surfactant-free precipitation route, J. Superlat. and Micro. 63 (2013) 258-266

[34] Y. Keereeta, T. Thongtem, S. Thongtem, Characterization of $\mathrm{ZnMoO}_{4}$ nanofibers synthesized by electrospinning-calcination combinations, Mater.Lett. 68 (2012) 265-268 


\section{Accepted Manuscript}

[35] Y. Liang, P. Liu, H. B. Li , and G. W. Yang, $\mathrm{ZnMoO}_{4}$ Micro- and Nanostructures Synthesized by Electrochemistry-Assisted Laser Ablation in Liquids and Their Optical Properties, J. Cryst.

Growth Des. 12 (2012) 4487-4493

[36] Gaoke Zhang, Shujie Yu, Yanqing Yang, Wei Jiang, Shuiming Zhang, Baibiao Huang, Synthesis, morphology and phase transition of the zinc molybdates $\mathrm{ZnMoO}_{4} \cdot 0.8 \mathrm{H}_{2} \mathrm{O} / \alpha-$

$\mathrm{ZnMoO}_{4} / \mathrm{ZnMoO}_{4}$ by hydrothermal method, J. Cryst. Growth 312 (2010) 1866-1874

[37] T. Söhnel, W. Reichelt, H. Oppermann, Hj. Mattauch, A. Simon, Zum System Zn/Mo/O. I. Phasenbestand und Eigenschaften der ternären Zinkmolybdate; Struktur von $\mathrm{Zn}_{3} \mathrm{Mo}_{2} \mathrm{O}_{9}$, Z. Anorg. Allg. Chem., 622 (1996), p. 1274

[38] W. Reichelt, T. Weber, T. Söhnel, S. Däbritz, Mischkristallbildung im System $\mathrm{CuMoO}_{4} / \mathrm{ZnMoO}_{4}$, Z. Anorg. Allg. Chem., 626 (2000) 2020-2027

[39] K. Pavani, A. Ramanan, Influence of 2-Aminopyridine on the Formation of Molybdates under Hydrothermal Conditions, Eur. J. Inorg. Chem., 2005 (2005) 3080-3087

[40] A.C. Larson, R.B. Von Dreele, General Structure Analysis System (GSAS), Los Almos Natl. Lab. LAUR, 23 (2000), pp. 86-748

[41] B. Toby, EXPGUI, a graphical user interface for GSAS, J. Appl. Crystallogr., 34 (2001), pp. 210-213

[42] J.F. Gouyet, Physical Fractal Structures, MASSON, Paris/Milan/Barcelone/Bonn, [43] D. Johnson, Zview, impedance software, Version 2.1a, Scribner Associates Inc, (1990-1998) [44] J. R. Macdonald, Electrical Response of Materials Containing Space Charge with Discharge at the Electrodes, J Chem. Phys, 54 (1971) 2026-2050

[45] J. R. Macdonald, Double Layer Capacitance and Relaxation in Electrolytes and Solids, Trans. Faraday Soc, 66 (1970) 943-958

[46] E. Barsoukov and J. R. Macdonald," Characterization of the electrical response of high resistivity ionic and dielectric solid materials by immittance spectroscopy" Eds., pp. 264-282, John Wiley \& Sons, New Jersey, NJ, USA, 2nd edition, 2005.

[47] C. Ho, I. D. Raistrick, and R. A. Huggins, “Application of A $\square$ C Techniques to the Study of Lithium Diffusion in Tungsten Trioxide Thin Films“, J. Electro. Soc. 127 (1980) 343-350.

[48] B. P. Mandal, S. K. Deshpande, and A. K. Tyagi, "Ionic conductivity enhancement in $\mathrm{Gd}_{2} \mathrm{Zr}_{2} \mathrm{O}_{7}$ pyrochlore by Nd doping”, J. Mater. Res. 23 (2008) 911-916.

[49] J.R. Macdonald, "Note on the parameterization of the constant-phase admittance element ", Solid State Ion. 13, (1984) 147-149 
[50] W. Wieczorek, J. Płocharski, J. Przyłuski, S. Głowinkowski, Z. Pajak, "Impedance spectroscopy and phase structure of PEO $\square$ NaI complexes “ Solid State Ion. 28 (1988) 1014-1017. [51 ] N. Ortega, A. Kumar, P. Bhattacharya, S.B. Majumder, R.S. Katiyar, Impedance spectroscopy of multiferroic $\mathrm{PbZr}_{\mathrm{x}} \mathrm{Ti}_{1-\mathrm{x}} \mathrm{O}_{3} / \mathrm{CoFe}_{2} \mathrm{O}_{4}$ layered thin films, Phys. Rev. B, 77 (2008), p. 014111 [52] Banarji Behera, P. Nayak, R.N.P. Choudhary, "Structural and impedance properties of $\mathrm{KBa}_{2} \mathrm{~V}_{5} \mathrm{O}_{15}$ ceramics", Mater. Res. Bull. 43 (2008) $401-410$ [53] A.K. Jonscher, "The 'universal' dielectric response" Nature 267, 673 (1977)

[54] C.K. Suman, K. Prasad, R.N.P. Choudhary, "Complex impedance studies on tungsten-bronze electroceramic: $\mathrm{Pb}_{2} \mathrm{Bi}_{3} \mathrm{LaTi}_{5} \mathrm{O}_{18}$ “ J. Mater. Sci. 41, (2006) 369 
Tables

Table 1: Refined structural parameters for triclinic $\alpha-\mathrm{ZnMoO}_{4}$ phase (space group P-1)

\begin{tabular}{|c|c|c|c|c|c|}
\hline $\mathrm{a}(\AA)$ & $\mathrm{b}(\AA)$ & $c(\AA)$ & $\alpha^{\circ}$ & $\beta^{\circ}$ & $\gamma^{\circ}$ \\
\hline $6.96168(7)$ & $8.36586(9)$ & $9.68981(8)$ & $96.7379(5)$ & $106.8614(7)^{\circ}$ & $101.7261(9)$ \\
\hline Atoms & $\mathbf{x}$ & $\mathbf{y}$ & \multicolumn{2}{|c|}{$\mathbf{z}$} & Uiso* $\left(\AA^{2}\right)$ \\
\hline $\operatorname{Mo}(1)$ & $0.0240(5)$ & $0.2979(4)$ & \multicolumn{2}{|c|}{$0.6227(2)$} & 0.00072 \\
\hline $\operatorname{Mo}(2)$ & $0.2994(4)$ & $0.3965(4)$ & \multicolumn{2}{|c|}{$0.1576(2)$} & 0.00404 \\
\hline $\operatorname{Mo}(3)$ & $0.5009(4)$ & $0.0192(3)$ & \multicolumn{2}{|c|}{$0.2497(3)$} & 0.00404 \\
\hline $\mathrm{Zn}(1)$ & $0.0331(6)$ & $0.1073(5)$ & \multicolumn{2}{|c|}{$0.2859(4)$} & 0.00401 \\
\hline $\mathrm{Zn}(2)$ & $0.4603(7)$ & $0.3059(5)$ & \multicolumn{2}{|c|}{$0.5151(4)$} & 0.025 \\
\hline $\mathrm{Zn}(3)$ & $0.7563(8)$ & $0.3074(7)$ & \multicolumn{2}{|c|}{$0.0997(6)$} & 0.025 \\
\hline $\mathrm{O}(1)$ & $0.0200(3)$ & $0.1440(9)$ & \multicolumn{2}{|c|}{$0.7326(12)$} & 0.025 \\
\hline $\mathrm{O}(2)$ & $0.0545(10)$ & $0.2794(14)$ & \multicolumn{2}{|c|}{$0.1516(13)$} & 0.0067 \\
\hline $\mathrm{O}(3)$ & $0.1420(2)$ & $0.4677(11)$ & \multicolumn{2}{|c|}{$0.7642(13)$} & 0.025 \\
\hline $\mathrm{O}(4)$ & $0.1487(12)$ & $0.2636(16)$ & \multicolumn{2}{|c|}{$0.4913(9)$} & 0.025 \\
\hline $\mathrm{O}(5)$ & $0.2540(3)$ & $0.5575(15)$ & \multicolumn{2}{|c|}{$0.0647(13)$} & 0.06541 \\
\hline $\mathrm{O}(6)$ & $0.2458(12)$ & $0.7170(2)$ & \multicolumn{2}{|c|}{$0.4608(14)$} & 0.025 \\
\hline $\mathrm{O}(7)$ & $0.3428(11)$ & $0.1393(15)$ & \multicolumn{2}{|c|}{$0.3079(11)$} & 0.025 \\
\hline $\mathrm{O}(8)$ & $0.362(2)$ & $0.8815(15)$ & \multicolumn{2}{|c|}{$0.0862(11)$} & 0.025 \\
\hline $\mathrm{O}(9)$ & $0.470(3)$ & $0.1629(13)$ & \multicolumn{2}{|c|}{$0.6756(13)$} & 0.02024 \\
\hline $\mathrm{O}(10)$ & $0.422(2)$ & $0.4603(8)$ & \multicolumn{2}{|c|}{$0.3525(6)$} & 0.025 \\
\hline $\mathrm{O}(11)$ & $0.4703(15)$ & $0.3012(18)$ & \multicolumn{2}{|c|}{$0.1061(15)$} & 0.025 \\
\hline $\mathrm{O}(12)$ & $0.7428(10)$ & $0.1449(14)$ & \multicolumn{2}{|c|}{$0.2497(13)$} & 0.025 \\
\hline $\begin{array}{l}\text { Reliability } \\
\text { factors }\end{array}$ & \multicolumn{5}{|c|}{ 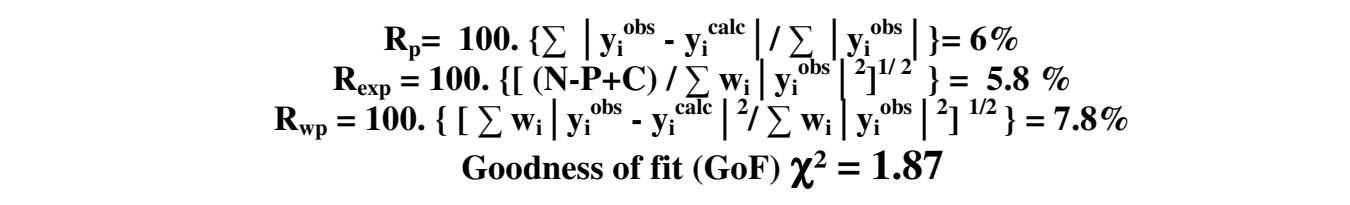 } \\
\hline
\end{tabular}

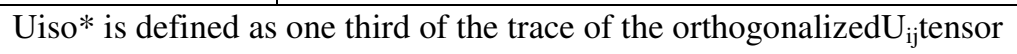


Table 2: Main interatomic distances $(\AA)$ for the $\alpha-\mathrm{ZnMoO}_{4}$ compound

\begin{tabular}{|c|c|c|c|}
\hline Mo1-O1 & $1.7566(1)$ & $\mathrm{Zn} 3-\mathrm{O} 11$ & $1.9957(1)$ \\
\hline Mo1-O3 & $1.7299(1)$ & $\mathrm{Zn} 3-\mathrm{O} 12$ & $2.1113(1)$ \\
\hline Mo1-O4 & $1.7564(1)$ & O1-Mo1 & $1.7566(1)$ \\
\hline Mo1-O6 ${ }^{\mathrm{i}}$ & 1.7791(1) & $\mathrm{O} 1-\mathrm{Zn} 1^{\mathrm{v}}$ & $2.0379(1)$ \\
\hline Mo2-O2 & $1.7613(1)$ & $\mathrm{O} 2-\mathrm{Mo} 2$ & $1.7613(1)$ \\
\hline Mo2-O5 & $1.7418(1)$ & $\mathrm{O} 2-\mathrm{Zn} 1$ & $2.0481(1)$ \\
\hline Mo2-O7 & $2.6748(1)$ & $\mathrm{O} 2-\mathrm{Zn}^{\text {iv }}$ & $2.0616(1)$ \\
\hline Mo2-O10 & $1.8030(1)$ & O3-Mo1 & $1.7299(1)$ \\
\hline Mo2-O11 & $1.7076(1)$ & $\mathrm{O} 3-\mathrm{Zn} 3^{\mathrm{vi}}$ & 2.0331(1) \\
\hline Mo3-O7 & $1.8050(1)$ & O4-Mo1 & $1.7564(1)$ \\
\hline Mo3-O $8^{\mathrm{ii}}$ & $1.7270(1)$ & O4-Zn1 & $2.0957(1)$ \\
\hline Mo3-O9iii & $1.7840(1)$ & $\mathrm{O} 4-\mathrm{Zn} 2$ & $2.0662(1)$ \\
\hline Mo3-O12 & $1.8024(1)$ & O5-Mo2 & $1.7418(1)$ \\
\hline $\mathrm{Zn} 1-\mathrm{Zn} 2$ & $3.1594(1)$ & O5-Zn3 $3^{\text {viii }}$ & $2.0670(1)$ \\
\hline $\mathrm{Zn} 1-\mathrm{Zn} 3^{\mathrm{iv}}$ & $3.1106(1)$ & $\mathrm{O} 6-\mathrm{Mo1}^{\mathrm{i}}$ & $1.7791(1)$ \\
\hline $\mathrm{Zn} 1-\mathrm{O} 1^{\mathrm{v}}$ & 2.0379(1) & O6-Zn2 ${ }^{\mathrm{vi}}$ & $2.0379(1)$ \\
\hline $\mathrm{Zn} 1-\mathrm{O} 2$ & $2.0481(1)$ & O7-Mo2 & $2.6748(1)$ \\
\hline $\mathrm{Zn} 1-\mathrm{O} 4$ & $2.0957(1)$ & O7-Mo3 & $1.8050(1)$ \\
\hline Zn1-O7 & $2.0685(1)$ & O7-Zn1 & $2.0685(1)$ \\
\hline $\mathrm{Zn} 1-\mathrm{O} 12^{\mathrm{iv}}$ & $2.0438(1)$ & $\mathrm{O} 7-\mathrm{Zn} 2$ & $2.1567(1)$ \\
\hline Zn2-Zn1 & $3.1594(1)$ & $\mathrm{O} 8-\mathrm{Mo3}^{\mathrm{ix}}$ & $1.7270(1)$ \\
\hline $\mathrm{Zn} 2-\mathrm{O} 4$ & $2.0662(1)$ & $\mathrm{O} 8-\mathrm{Zn} 3^{\text {viii }}$ & $2.0874(1)$ \\
\hline $\mathrm{Zn} 2-\mathrm{O6}^{\mathrm{vi}}$ & $2.0379(1)$ & O9-Mo3 $3^{\text {iii }}$ & $1.7840(1)$ \\
\hline $\mathrm{Zn} 2-\mathrm{O} 7$ & $2.1567(1)$ & O9-Zn2 & $2.0540(1)$ \\
\hline $\mathrm{Zn} 2-\mathrm{O} 9$ & $2.0540(1)$ & $\mathrm{O} 10-\mathrm{Mo} 2$ & $1.8030(1)$ \\
\hline Zn2-O10 & $2.1469(1)$ & O10-Zn2 & $2.1469(1)$ \\
\hline $\mathrm{Zn} 2-\mathrm{O} 10^{\mathrm{vi}}$ & $2.0678(1)$ & $\mathrm{O} 10-\mathrm{Zn} 2^{\mathrm{vi}}$ & $2.0678(1)$ \\
\hline Zn3-Zn1 $1^{\text {vii }}$ & $3.1106(1)$ & O11-Mo2 & $1.7076(1)$ \\
\hline $\mathrm{Zn} 3-\mathrm{O} 2^{\mathrm{vii}}$ & $2.0616(1)$ & $\mathrm{O} 11-\mathrm{Zn} 3$ & $1.9957(1)$ \\
\hline $\mathrm{Zn} 3-\mathrm{O}^{\mathrm{vi}}$ & 2.0331(1) & O12-Mo3 & $1.8024(1)$ \\
\hline Zn3-O5 $5^{\text {viii }}$ & $2.0670(1)$ & $\mathrm{O} 12-\mathrm{Zn} 1^{\text {vii }}$ & $2.0438(1)$ \\
\hline $\mathrm{Zn3-O8^{ \text {viii } }}$ & $2.0874(1)$ & O12-Zn3 & $2.1113(1)$ \\
\hline
\end{tabular}

Symmetry codes: (i) $-\mathrm{x},-\mathrm{y}+1,-\mathrm{z}+1$; (ii) $\mathrm{x}, \mathrm{y}-1, \mathrm{z}$; (iii) $-\mathrm{x}+1,-\mathrm{y},-\mathrm{z}+1$; (iv) $\mathrm{x}-1, \mathrm{y}, \mathrm{z}$; (v) $-\mathrm{x},-\mathrm{y},-\mathrm{z}+1$; (vi) $-\mathrm{x}+1,-\mathrm{y}+1,-\mathrm{z}+1$; (vii) $\mathrm{x}+1, \mathrm{y}, \mathrm{z}$; (viii) $-\mathrm{x}+1,-\mathrm{y}+1,-\mathrm{z}$; (ix) $\mathrm{x}, \mathrm{y}+1, \mathrm{z}$ 
Table 3: Electrical characteristics of ZMO-600 pellet. Bulk impedance analysis: CPE terms $\mathrm{A}$ (in $\Omega^{-1} \cdot \mathrm{Hz}^{-\mathrm{n}}$ unit) and $\mathrm{CPE}$ exponents $\mathrm{n}$, as a function of temperatures $300^{\circ} \mathrm{C} \leq \Theta \leq 700^{\circ} \mathrm{C}$. Model: $1 / Z=1 / R+A .(j \omega)^{n}$

\begin{tabular}{|c|c|c|c|}
\cline { 2 - 4 } \multicolumn{1}{c|}{} & \multicolumn{3}{c|}{ Bulk material analysis } \\
\hline$\Theta\left({ }^{\circ} \mathrm{C}\right)$ & $\mathrm{n}$ & $\mathrm{R}(\Omega)$ & $\begin{array}{l}\mathrm{A}\left((\mathrm{Hz})^{-\mathrm{n}} . \Omega^{-1}\right)( \\
\left(10^{-11}\right)\end{array}$ \\
\hline 300 & 0.68 & $1.70 .10^{8}$ & 1.39 \\
\hline 320 & 0.69 & $8.80 .10^{7}$ & 1.48 \\
\hline 340 & 0.70 & $5.08 .10^{7}$ & 1.46 \\
\hline 360 & 0.69 & $2.79 .10^{7}$ & 1.47 \\
\hline 380 & 0.69 & $1.55 .10^{7}$ & 1.45 \\
\hline 400 & 0.68 & $8.61 .10^{6}$ & 1.45 \\
\hline 420 & 0.69 & $4.84 .10^{6}$ & 1.45 \\
\hline 440 & 0.72 & $3.30 .10^{6}$ & 1.44 \\
\hline 460 & 0.68 & $1.40 .10^{6}$ & 1.46 \\
\hline 480 & 0.67 & $6.59 .10^{5}$ & 1.47 \\
\hline 500 & 0.64 & $3.43 .10^{5}$ & 1.46 \\
\hline 520 & 0.63 & $1.95 .10^{5}$ & 1.45 \\
\hline 540 & 0.64 & $1.20 .10^{5}$ & 1.47 \\
\hline 560 & 0.64 & 75877 & 1.48 \\
\hline 580 & 0.66 & 49586 & 1.52 \\
\hline 600 & 0.68 & 33614 & 1.57 \\
\hline 620 & 0.71 & 22843 & 1.65 \\
\hline 640 & 0.72 & 15734 & 1.75 \\
\hline 660 & 0.72 & 10965 & 1.77 \\
\hline 680 & 0.70 & 8942.2 & 1.72 \\
\hline 700 & 0.81 & 6350.3 & 2.75 \\
\hline & & & \\
\hline
\end{tabular}


Accepted Manuscript

Table 4: Warburg parameters $R_{W}, A_{W}$ and $m$, as a function of temperatures $300^{\circ} \mathrm{C} \leq \Theta \leq$ 700 $^{\circ} \mathrm{C}$ for the third cycle. Model: $\mathrm{Z}_{\mathrm{W}}=\mathbf{R}_{\mathrm{W}} \cdot \operatorname{Tanh}\left[\left(\mathbf{j} \mathrm{A}_{\mathrm{W}} \omega\right)^{\mathrm{m}}\right] /\left(\left[\left(\mathbf{j} \mathrm{A}_{\mathrm{W}} \omega\right)^{\mathrm{m}}\right)\right.$

\begin{tabular}{|c|c|c|c|}
\hline$\Theta\left({ }^{\circ} \mathrm{C}\right)$ & $\mathrm{R}_{\mathrm{W}}(\Omega)$ & $\mathrm{m}$ & $\mathrm{A}_{\mathrm{W}}$ in $10^{-3} \mathrm{~s}$ \\
\hline 420 & $3.27 .10^{6}$ & 0.14 & 24.96 \\
\hline 440 & $1.59 .10^{6}$ & 0.19 & 7.00 \\
\hline 460 & $1.16 .10^{6}$ & 0.19 & 3.00 \\
\hline 480 & 561040 & 0.21 & 2.15 \\
\hline 500 & 297264 & 0.22 & 1.75 \\
\hline 520 & 175130 & 0.24 & 1.25 \\
\hline 540 & 109280 & 0.25 & 1.02 \\
\hline 560 & 70971 & 0.25 & 0.87 \\
\hline 580 & 47572 & 0.25 & 0.83 \\
\hline 600 & 32335 & 0.23 & 0.80 \\
\hline 620 & 22514 & 0.21 & 0.88 \\
\hline 640 & 15746 & 0.19 & 0.85 \\
\hline 660 & 11171 & 0.19 & 1.40 \\
\hline 680 & 8020 & 0.17 & 2.15 \\
\hline
\end{tabular}


Table 5: Activation energies associated with bulk and Warburg components.

\begin{tabular}{|l|c|c|c|}
\cline { 2 - 4 } \multicolumn{1}{c|}{} & \multicolumn{2}{|l|}{ Temperature range } & \multicolumn{2}{|l|}{ Activation energies (eV) } \\
\cline { 2 - 4 } & Arrhenius test & $\log (\sigma)$ & $\log (\sigma \mathrm{T})$ \\
\hline Bulk characteristic & $573<\mathrm{T}<733$ & $1.16(7)$ & $1.21(8)$ \\
\cline { 2 - 4 } & $753<\mathrm{T}<973$ & $1.61(10)$ & $1.69(10)$ \\
\hline Warburg component & $753<\mathrm{T}<953$ & $1.3(0.1)$ & $1.4(0.1)$ \\
\hline
\end{tabular}

Table 6: parameters of modeled conductivity

\begin{tabular}{|c|c|c|c|c|}
\hline & $\mathbf{A}_{\mathbf{1}}$ & $\mathbf{A}_{\mathbf{2}}$ & $\mathrm{E}_{\mathbf{1}}(\mathbf{e V})$ & $\mathbf{E}_{\mathbf{2}}(\mathbf{e V})$ \\
\hline T<Tc (Triclinic) & 100 & $10.10^{6}$ & 0.93 & 1.65 \\
\hline & $\mathbf{A}_{\mathbf{1}}{ }^{\prime}$ & $\mathbf{A}_{\mathbf{2}}$ & $\mathrm{E}_{\mathbf{1}}{ }^{\prime}(\mathbf{e V})$ & $\mathrm{E}_{\mathbf{2}}{ }^{\prime}(\mathbf{e V})$ \\
\hline T>Tc (Monoclinic) & 300 & $30.10^{6}$ & 0.83 & 1.86 \\
\hline
\end{tabular}


Figures

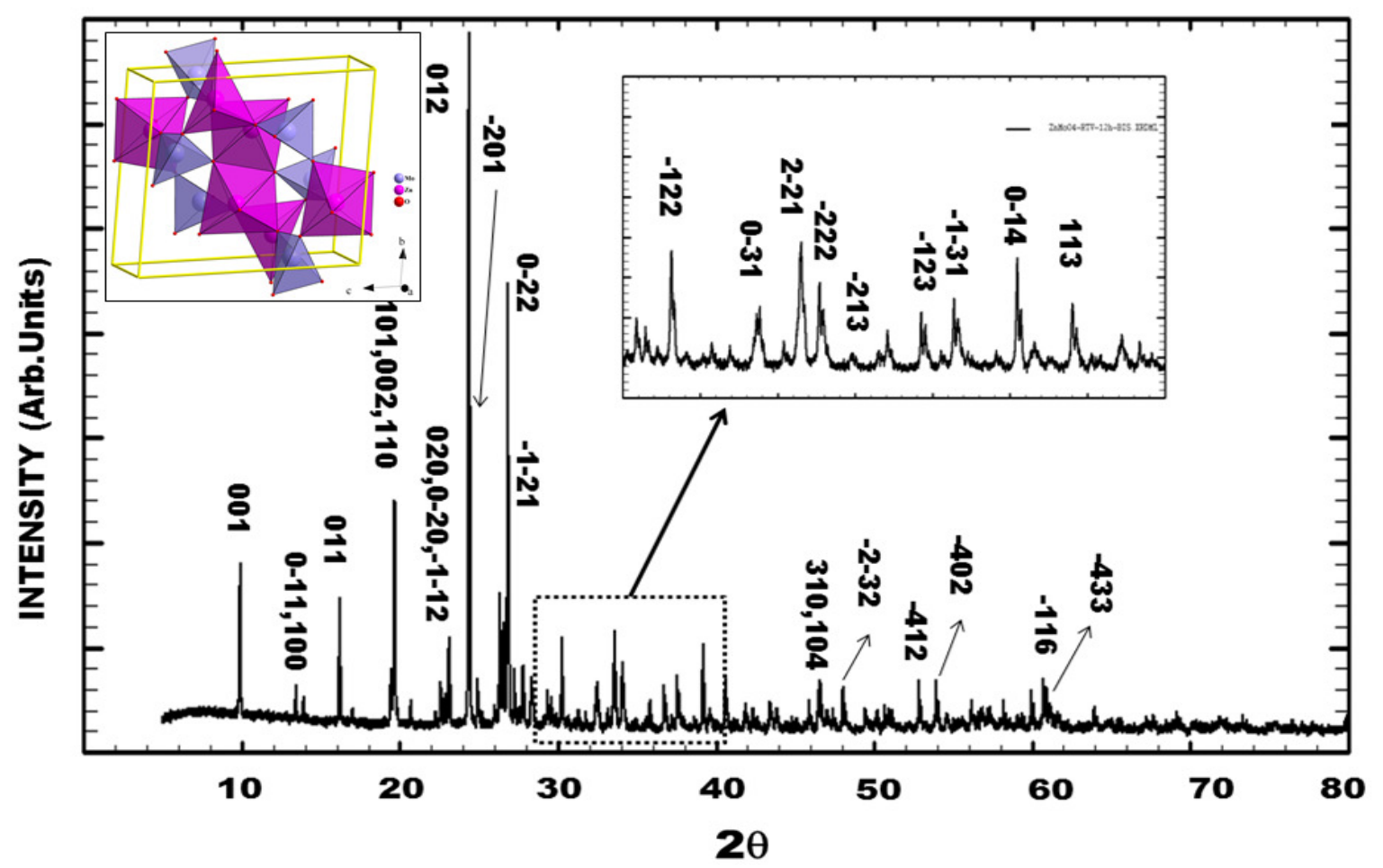

Figure 1: XRD pattern of $\alpha-\mathrm{ZnMoO}_{4}$ obtained in room conditions, after thermal treatments at $600^{\circ} \mathrm{C}$, during 3 hours. 
Accepted Manuscript

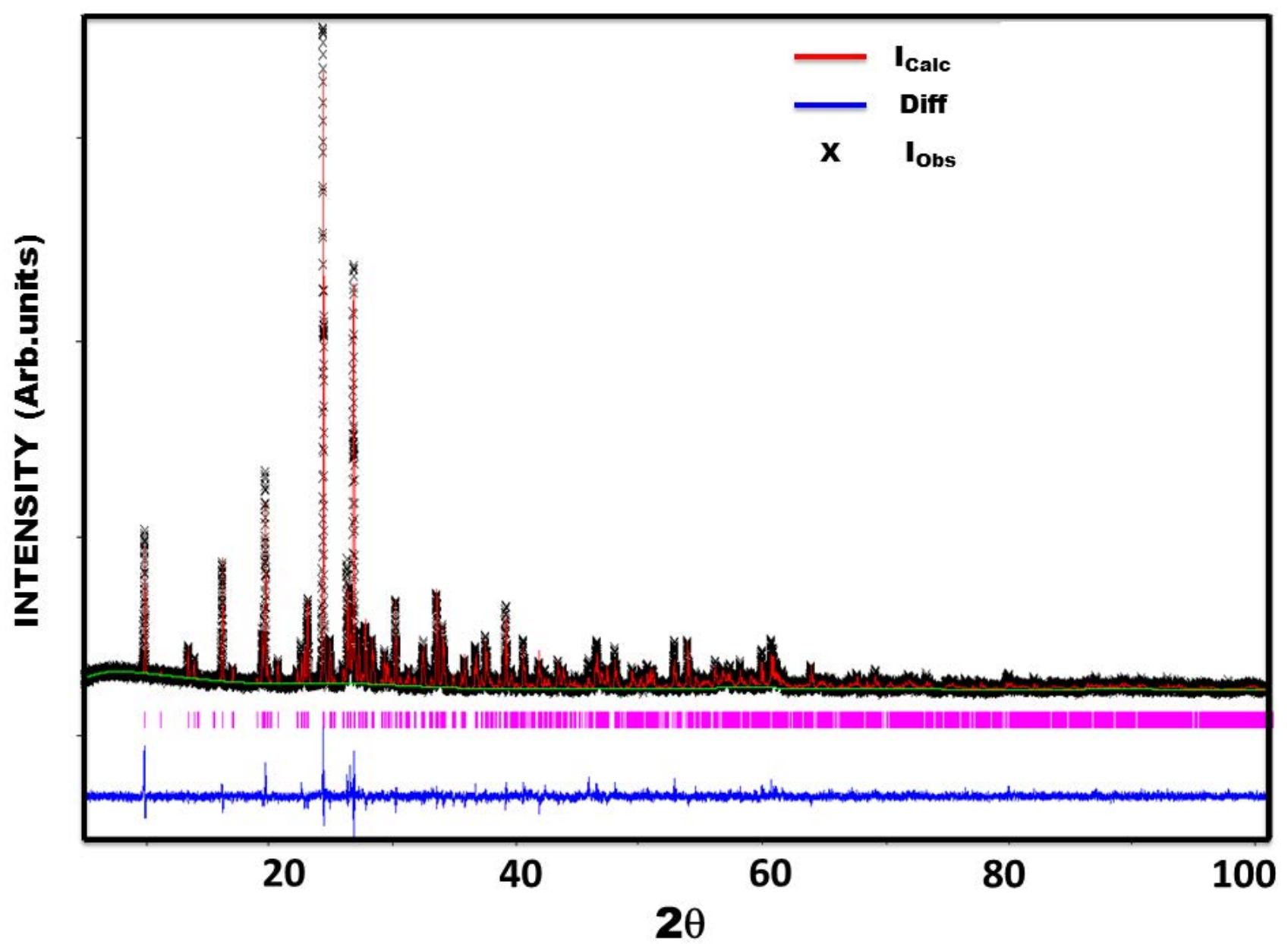

Figure 2: Calculated and observed diffraction profiles, from XRD Rietveld refinements of $\alpha-\mathrm{ZnMoO}_{4}$ thermally treated at $600^{\circ} \mathrm{C}$. 

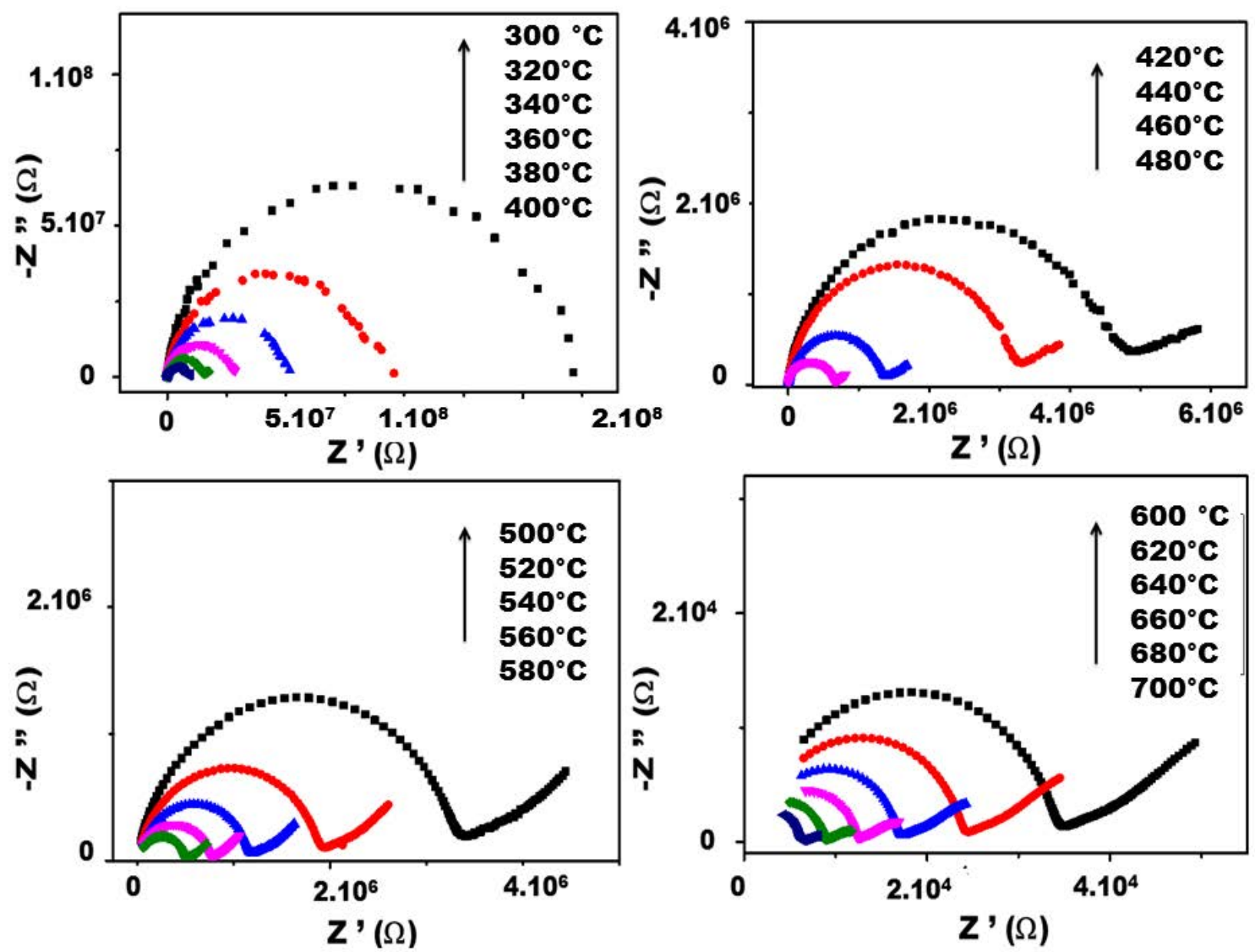

Figure 3: Nyquist representation for the $\alpha-\mathrm{ZnMoO}_{4}$ sample, as a function of temperature $300^{\circ} \mathrm{C} \leq \Theta \leq 700^{\circ} \mathrm{C}$. 


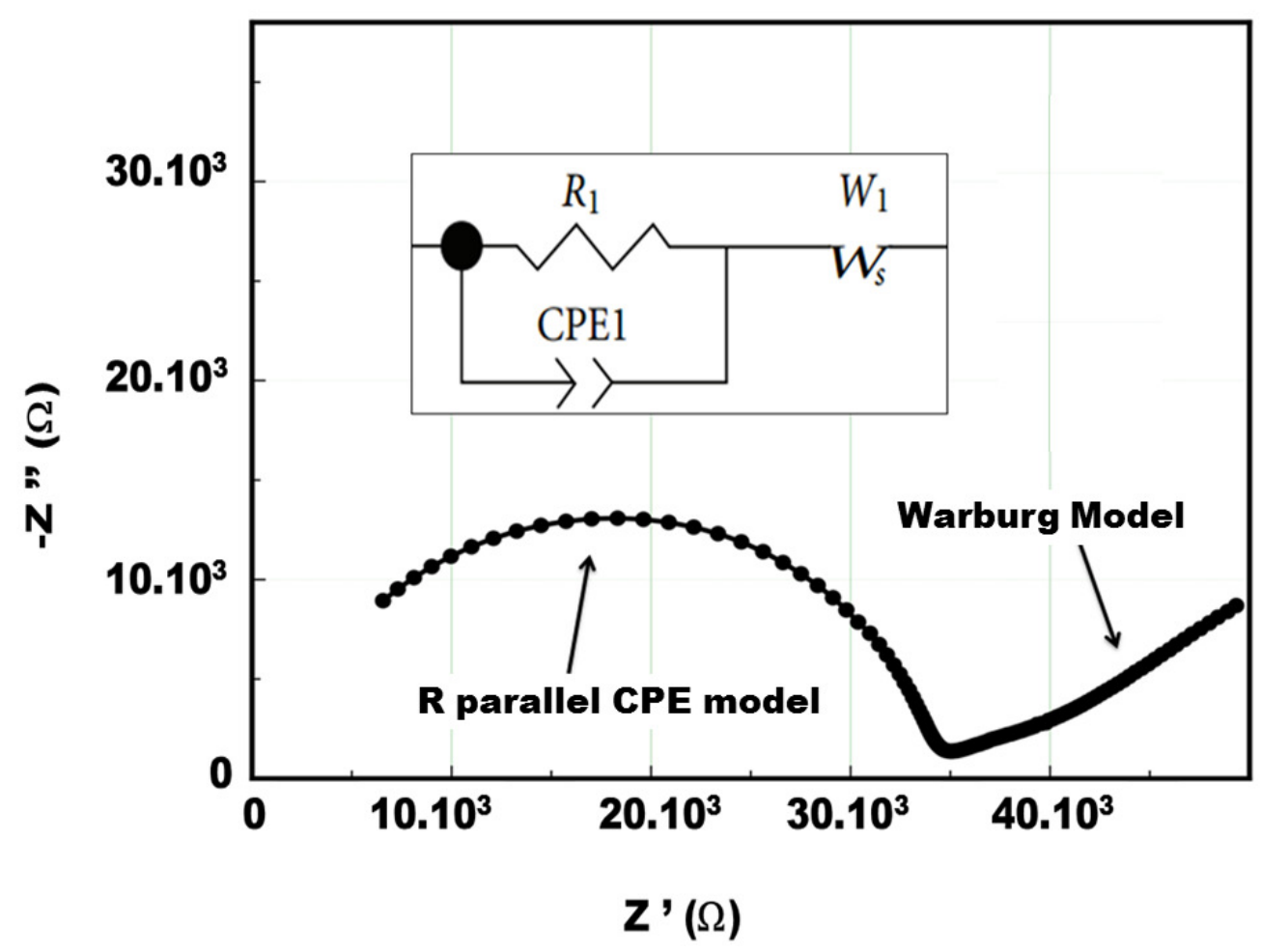

Figure 4: Fit of Nyquist data obtained at $600^{\circ} \mathrm{C}$, for the $\alpha-\mathrm{ZnMoO}_{4}$ sample; equivalent circuit (inset) with Warburg component. 

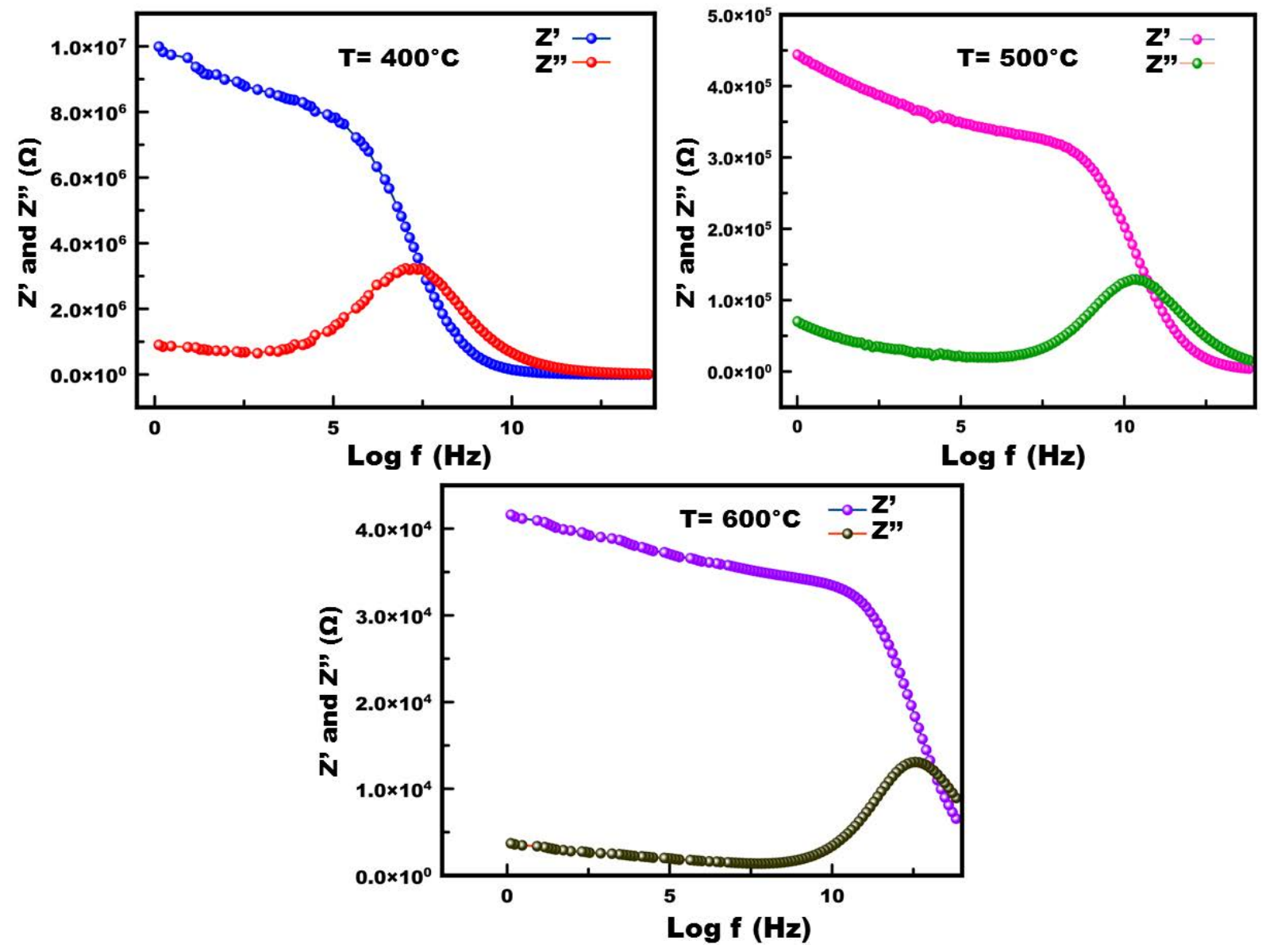

Figure 5: Variation of real and imaginary impedance (i.e $Z$ ' and Z') with frequency at selected temperatures. 

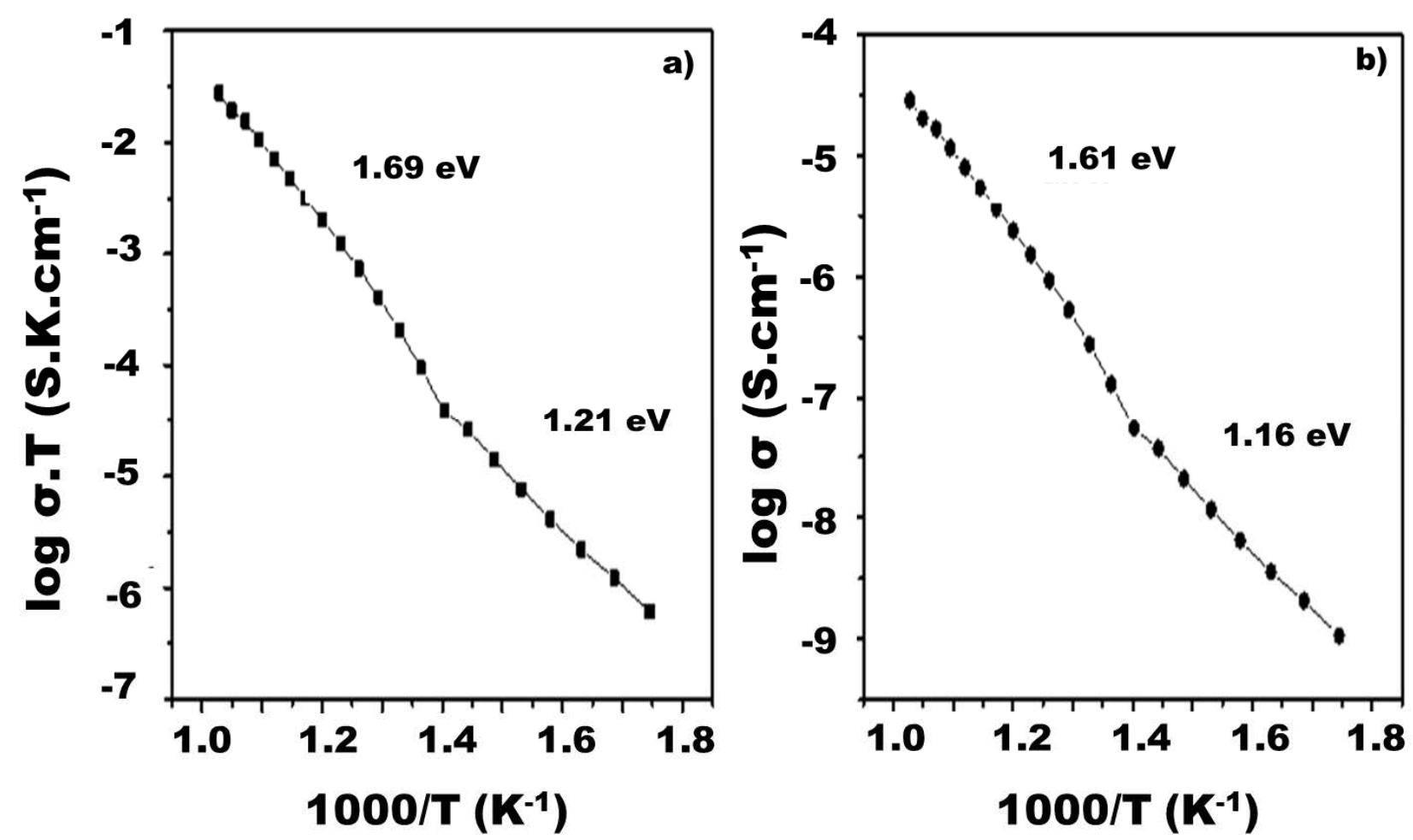

Figure 6: Evolution of sample conductivity in two Arrhenius representations, (a) $\log (\sigma)$ and (b) $\log (\sigma . \mathrm{T})$ versus $1 / \mathrm{T}\left(\mathrm{K}^{-1}\right)$. Activation energies determined in the linear parts of the curves.

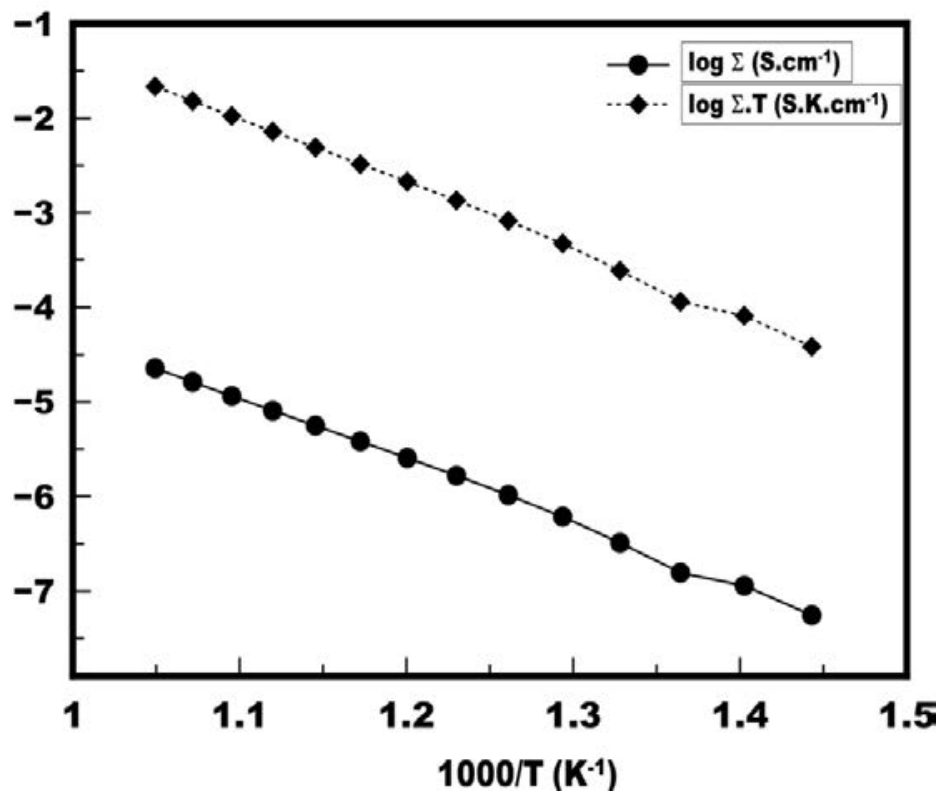

Figure 7: Evolution of Warburg conductance in two Arrhenius representations: $\log (\Sigma)$ and $\log (\Sigma . \mathrm{T})$ versus $1 / \mathrm{T}\left(\mathrm{K}^{-1}\right)$ 
Accepted Manuscript

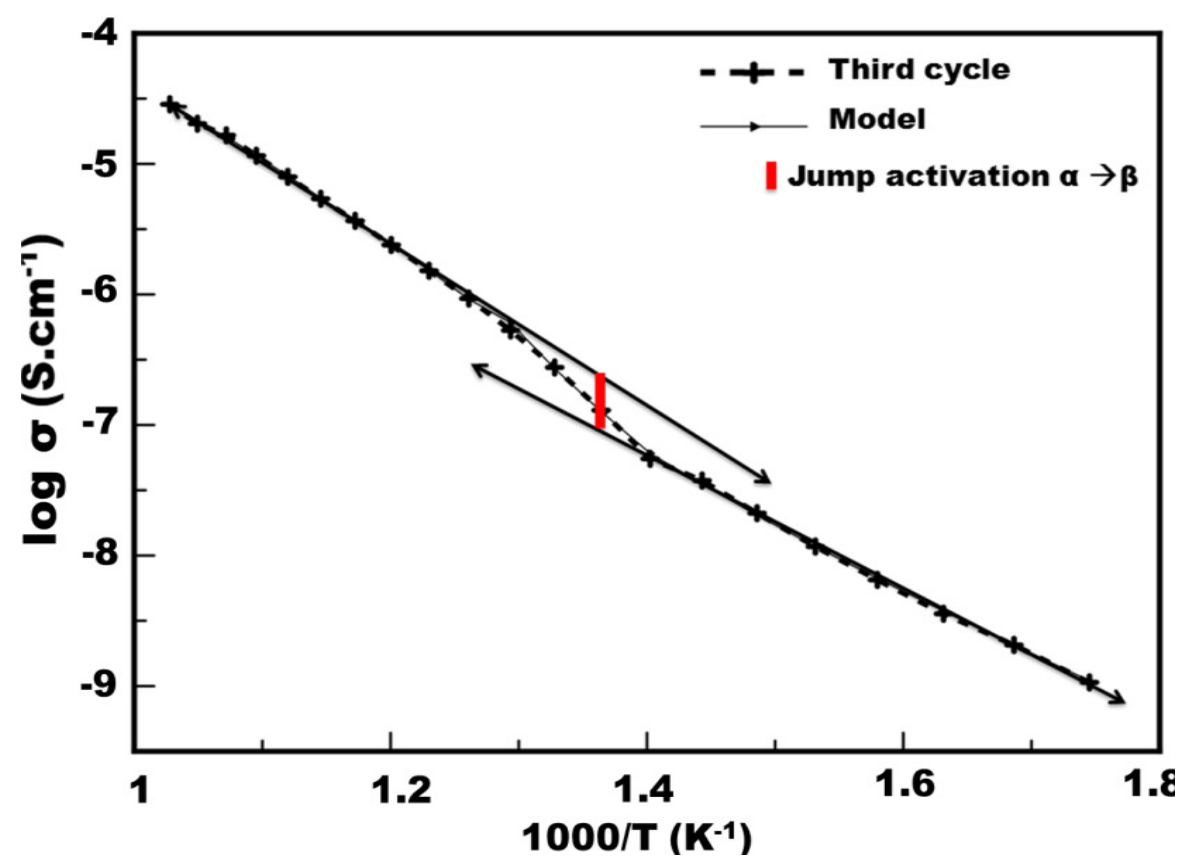

Figure 8: The calculated curve $\log (\sigma)$ using the proposed model as a function of $1 / \mathrm{T}\left(\mathrm{K}^{-1}\right)$ 